\title{
An Analysis of Characteristics and Relationships of the Characters in the Big Bang Theory from the Perspective of Turn-taking Mechanism
}

\author{
Tingting Shi \\ Shanxi Normal University, Linfen, China
}

\begin{abstract}
Turn-taking mechanism was proposed by Harvey Sack and his colleagues in the 1790s, and it was the central part of conversation analysis. The researchers at home and abroad have started to make a research on it after them. The researchers abroad investigated it from the institutional talk, such as TV, telephone talk and doctor patient interaction, and so on. Others, the researchers at home mainly published some articles without analyzing the specific conversations based on the foreign studies. The paper will analyze the characters' relationships and characteristics in the Big Bang Theory from the perspective of turning-taking mechanism. The significance of the study is to make people understand the features of the conversation. From the perspective of pragmatics, we will analyze the turn-taking mechanism, with which we can study the rule of using language.
\end{abstract}

Index Terms - turn-taking mechanism, the sitcom, the Big Bang Theory, the characters' relationships and characteristics

\section{INTRODUCTION}

This part is the guide of the paper, and it gives a brief introduction to the paper. The purpose of the study is to use turn-taking mechanism to analyze the sitcom The Big Bang Theory, and to study characteristics of characters through the analysis of the sitcom, also to observe the relationship between them. The paper is composed of five parts.

Turn-taking mechanism as the crucial part in the conversational analysis was put forward by Harvey Sacks and his colleagues Emannal Schegloff, and Gail Jefferson in the early 1970s. Then many scholars all over the world focus on it and made a great contribution in this field. At the beginning of it, the main task of their study analyzes the conversations between doctors and patients by using the conversational analysis theory. Later on, with the development of the society, many researchers start to analyze some new objects such as the conversations in the TV series and TV program.

Since the turn-taking theory is introduced into China, it arouses many scholars interested in it and pay attention to it. Also, some scholars make a great effort to it, such as Zhang Tingguo, Ji Daohong, and Chen Jianguo. They provide many valuable works for the present study.

From the perspective of the Pragmatics and turn-taking mechanisms, the main purpose of the study is that using the turn-taking mechanisms to analyze the conversations in the sitcom to discover their characteristics and relationships in the sitcom.

The significance of the paper is that it can help people to learn characteristics and relationships in the sitcom by analyzing their conversations using the turn-taking mechanisms. Some searchers have been doing a lot in this field but some parts still remind to be improved. It will be enriched the turn-taking theory, and widen the research scope by studying turn-taking theory in the sitcom.

Recently, sitcom becoming more and more popular in the world, and has aroused many scholars interested in it. People will have a better understanding about the essence of the sitcom and the language usage by study it from the perspective of the linguistics.

\section{LITERATURE REVIEW}

Part two is literature review, there are two sections in the part, the first section is the introduction of turn-taking mechanism, when it comes to talk about it, people must think of turn that is very important unit in our daily conversation, and it plays a significant role in our talking. The second section is to introduce the sitcom: the Big Bang Theory. The sitcom spreads fast in the worldwide, and it catches people' eyes and many researchers pay attention to it, and help readers understand the essence of the sitcom.

\section{A. Turn-taking Mechanism}

This part is a brief introduction of turn-taking mechanism and a survey of previous studies on turn-taking mechanism at home and abroad.

\section{A Brief Induction of Turn- taking Mechanism}


Turn-taking mechanism was used in our daily conversation. And it comes from the conversation analysis (CA) which is the important study in pragmatics. CA refers to the analysis of the conversation in order to find out conversation characteristics and how to use the characteristic of conversation in daily life. It includes the study of how speakers decided to speak during conversation, and how the expressions of two or more speakers are related, and the different functions that conversation is used for. American socialist Harvey Sacks and his partners Emannel Schegloff, Gail Jefferson was famous in the study. It was based on daily conversation, the studies of turn-taking mechanisms which deal with the problem about changing speakers in dialogue. Conversation forms the natural way of oral behaviors. Even though the conversation is a casual way in communication but it has its own rules. We can find out regulars though many areas.

\section{A Brief Introduction Survey of Previous studies on Turn-taking Mechanism at Abroad and Home}

When it comes to talk about turn-taking mechanism, there are some famous people in the field abroad.

Firstly, Nofsigner believes that turn-taking make use of the different length of four units. The first consists of independent words such as "Yes", the second makes use of phrases like "in the desk" and the structure does not include subject and object. The third consists of clause, and the last make use of a complete sentence such as "the men who received".

Secondly, about the components of turn-taking, Fasold also has the similar expression and he proposes turns are constructed of units for which turned out to be syntactic units: words, phrase, and clauses.And Sacks, Schegloff and Jefferson put forward the rule of turn 2 constructions and the rule of allocation, both of them have a significant meaning.Other scholars like Harries(1951) defined the turn "as a stretch of talk, by one person, before and after which is silence on the part of that person."(Harris, 1951, p. 14)

Also, some contributions made in our country. Zhang Tingguo (2003) delivers his paper turn and the Communication strategy of turn-taking and put forward turn-taking form and process in it. Ji Daohong publishes the paper Analysis of Turn-taking Skills and talks over the turn-taking skills and principles among interlocutors in conversation from the aspects of claiming a turn, holding a turn and yielding a turn, Chen Jianguo delivered his writing and discusses seven hidden rules such as space, sequence, help, avoidance, focus-balance, elimination and control.

\section{B. The Sitcom: The Big Bang Theory}

This part is a brief introduction of the Big Bang theory and a survey of previous studies on sitcom at home and abroad.

\section{A Brief Introduction of the Big Bang Theory}

The Big Bang Theory was firstly played by the American company CBC on Sep. 24, 2007, and produced by Chuck Lorre Productions and Warner Bros, and it is directed by Mark Cendrowski and acted by some famous actors, Jim Parsons, Johnny Calecki, Kaley Cuoco, Simon Helberg, Mayim Bialik, Kunal Nayyar, Melissa Rauch and so on. It is so popular that the viewership has been raised to 200 million and also got a lot of rewards. The show has been updated to eight season and many fans followed it from start to end.

It tells a story between two men with their neighbor, who is a beautiful girl. These boys have high intelligence quotient, and the girl has totally different life with them. Her career is not very good and working in a restaurant, just like other girls, she also pursuits the fashion things and love to go shopping. Later, she falls in love with Leonard. Leonard and Sheldon, these two persons are the roommate. Both of them have high intelligence quotient, but Sheldon has a lower emotional quotient, the character acted by Jim Parsons. Leonard Leakey Hofstadter is a man with IQ 173, who is acted by Jonny Galecki. And with the development of the plot, Sheldon also has a girlfriend, Amy. The girl has the similar characteristics with Sheldon, and she loves her boyfriend so much.

\section{A Brief Survey of Previous Studies on Sitcom at Home and Abroad}

Sitcom is transformed by the word "situation comedy". With the developed of the globalization, it spreads into many countries from America. However, it is not easy to make a definition to it. Just as Feuer said, "sitcoms like other series of TV", it depends on work fields, TV report and the sense of public, and it also changes with the development of society. This is a kind of comedy is virtually real life and make humors by players, and it always development around some details in the family. The most of America sitcom is family sitcom. There are famous family sitcoms such as I Love Lucy, The Simpsons, Taxi and Old Friends. The most significant character not only entertains people but also has other features. Baker who is the researcher of sitcom lists nine properties:

(i) It plays 24-30 minutes and it is series not serial.

(ii) It often plays on indoors and has fixed figures, family scenes.

(iii) The program often around one or a couple of leading stars and other people plays a minor role.

(iv) The minor role always has a rigid image.

(v) It often plays on house or office on playground.

(vi) The theme is family or symbolic family.

(vii) Every program has traditional structures: tranquil, conflict.

(viii) It has a circle: scene and heroes will back the start place when it's ending.

(ix) The thread of a story has the same development: repetitive behaviors, pet phrase.

Most sitcoms in America have these features. However, there are some exceptions, and it changes with the society and its own features. 
Nowadays, sitcom has been accepted by many countries and it becomes popular in the world. It is one of the most welcomed TV programs in many countries where English is their native language, such as, British, Australia, and Canada.

\section{TheOretical FramewOrk OF THE PRESENT StUdy}

Part three is the theoretical framework of turn-taking mechanism. This part will introduce turn-construction unit, turn allocation components, adjacency pairs, preference structure and presequences and also give some examples to illustrate it.

\section{A. Turn-taking Mechanism}

Turn-taking is the minimal part in the structure of conversation and makes use of sentences, clauses, words and a lot of structures. It refers to that participates activity in the conversation and starts from speaking to ending or stopped by others (including interrupting by listeners and replaced) during the whole conversation. Turn-taking has short and long sentence, and it has no limit in arrangement. There is a topic used to discuss by speakers and listeners in communication. Mostly, participants use the communicating format of conversation likes a-b-a1-b1 when they are talking with each other. The speaker starts speaking to change their topic, it is a turn-taking. If participates are still talking, they end up one topic and turn to another until the whole conversation end. During the conversation, it must find out a proper topic in order to make sure turn-taking fluency.

\section{Turn-construction Units}

There are two components in the turn-taking system according to conversational analysis, one is the allocation mechanisms which are responsible for distributing a turn, and the other is the lexical components, there are different types uttered by speaker can construct turns.

These basic units are known as turn construction unit. These unit types include in lexical, clausal, phrasal, and sentential. But at the same time, Liu Qingling(2012) "feedback units are included in verbal behavior feedbacks and non-verbal feedbacks in our daily life and that use to a turn". (Liu Qingling, 2012, p.194.)

1. The different kinds of language units

(i) Word serves as a turn. For example,

A: Can you open a door?

B: Ok.

The listener's answer just use one word but the two speakers attend this conversation, so it can construct a turn.

(ii) Phrase serves as a turn. For example,

A: Do you know where is my key?

B: On the desk.

The listener tells the place of the key, and uses a clause to express it. The topic is around one point, and the two speakers participate the dialogue that is a whole turn.

(iii) Sentence serves as a turn. For example,

A: Where did you go at the summer holiday?

B: Oh, I went to famous spots, such as the Great Wall and Tian'an Men Square.

In this conversation, the listener uses a relevance sentence to respond to the speaker, so the whole turn was made of sentence.

2. The verbal behavior feedback unit

We usually call the verbal behavior feedback unit as the response after listening. It may be a modal particle, such as ah; or may be a word expression term, such as yeah; may also be a phrase, such as I see, I can. In the sitcom, there are so many cases, such as Sheldon's answer just has a modal particle in the conversation, Ah-ah-ow-oo, so it is a turn.

3. Non-verbal behavior feedback unit

It is usually represent a series of physical behavior, such as gestures, head-nod and eye-contact and so on. Speaker can use some language features to interrupt other's words, such as tone-raising with the help of the gesture to achieve speaker's purpose and people use these information to express his attitude, so we can find his inner world from his attitude.

\section{Turn-allocation Components}

And turn-allocation components explain the speaker and the hearer organize their words by distributing turns to the speaker. It often occurred that the speaker believes the conversation will be finished so it asks the participants must have the ability to observe the content of the conversation.

Liu Runqing (2012), said "turn-allocation techniques can be divided into two parts: one part is that the speaker chooses someone to talk about the topic sequentially, and the other part is that the speaker ended a turn by self-selection" (Liu Qingling, 2012, p.194). According to Sack et al (1974), "turn-allocation techniques are actually used in conversation and they distinguish them into two categories as "current selects next" and "self-selection"” (Sacks et al., 1974, p.703), for example, the following is the example to show "current selects next".

A: What are you doing?

B: I am reading. 
A: What kind of it?

B: It is about science.

In this conversation, the speaker selects the listener by asking a question, this is a way of "current selects next." At the same time, the speaker A asks another question to B selects him as the next again. The following is example to show "self-selection."

A: There are discounting.

B: Where?

A: The supermarket at the main street.

In this conversation, the speaker starts a topic and selects a person to continue the dialogue. The listener only repeat some parts of the prior utterance with only one word to ask the speaker and the speaker answer the question to finish the topic. This is "self-selection."

\section{B. Sequence Organization}

Because of the complexity of oral behavior, the pattern of turn-taking has various ways. There are two common forms of turn-taking adjacency pairs and insertion sequence.

\section{Adjacency Pair}

One useful mechanism in the convert of conversation is that one turn has a special following answer. The following is always the response to the preceding. Greeting to greeting in a phatic, question to answer, and invitation by accepting or refusal, and so on. The sequence is called adjacency pair: two different speakers make a sequence of two related expressions. (Liu Runqing, 2006, p.183). For example in (1), A makes a question and B replies with an affirmation.
A: Are you a student?
Question
First pair part
B: Yes, I am.
Answer
Second pair part

Here the question and answer is an adjacency pair.

Adjacency pair has five characteristics:

i. Adjacency pair makes use of two expressions, a first and a second part.

ii. The two parts are spoken by two different speakers.

iii. The two expressions belong to specific types, for example, question to answer, or greeting to greeting.

iv. The second part always related to the first part.

$\mathrm{v}$. The form and content of the second part depends on the type of the first part.

Adjacency pair has many types, however, the second part always responds to the first part immediately. We always see that a question-answer sequence will be delayed while another question-answer sequence intervenes. The sequence will take the form of Q1-Q2-A2-A1. The middle part Q2 and A2 is the insertion sequence.

An insertion sequence is one adjacency pair within another. For example:

A: Do you want to early flight?

B: What time it does arrive?

A: Ten forty.

$\mathrm{B}$ : Ok, that is great.

The sequence takes form of Q1-Q2-A2-A1. And the part Q2-A2 is called insertion sequence. So it is an adjacency pair within another.

\section{Preference Structure}

In an adjacency pair, the listener does not always agree with the speaker's opinions and then it forms two kinds of answers that the one is preferred and the other is disagreement. For thus, a question should be contained by:

i. A question

ii. A part of an answer

iii. By a denial of the question

iv. By a statement of ignorance

For example:

Sheldon: I am in Kingman, Arizona, and I need you to pick me up.

Leonard: Ok, I will pick you.

Leonard: I would love to, but I am just about to do yoga with Penny.

-- (The Big Bang Theory Season 8 Episode 1)

In this conversation, we can observe that there are two answers to one question, but they are not equal status. The first answer is that Leonard agreed with Sheldon's demand and go to pick him. But the second answer is that Leonard refused Sheldon by an indirectly way. So, the first answer is a preference. As we all know, adjacency pair is two utterances and the second part is related to the first part. Many answers to the first part not only can be an agreement but also a denial of the relevance of the question for example (1),

A: Do you want to drink a cup of tea with me?

B: I do not want to go.

On the basis of this observation, it suggests that there can be several different answers to the first part, but they are not equal status.

\section{Presequences Organization}


Presequence is the way to open a conversation when people desire to get something or want to ask others to help themselves. Thus, they must communicate with each other, and we should express our politeness, avoiding rudeness or impoliteness, and the way we use to open conversation and taking some potential actions is called presequence.

We should say hello to our friends when we meet them after a long time. This is greeting. Greeting uses to establish an atmosphere between the speaker and the listener, and maintain a set of relationship. Different countries have different ways of greeting. For example, people in English often talk about weather when they meet with each other. However, people live in China always say, "Where are you going? Have you finished your lunch? And what are you doing now?" But, there is difference between greeting and presequence. Presequence is used by a person who wants to ask others to help him or get something from others indirectly to open conversation. For example,

A: It is a nice day, is not it?

B: Actually it is.

A: I want to a supermarket but my car is not here. Would you like to borrow your car for me?

B: Ok, it's over there.

Here, A wants to borrow B's car and he does not say it directly and at the beginning, he asks whether to open the conversation. So this is presequence. In fact, we often use the way to start our communication. And there are many types of presequences.

\section{AnAlysis of the Relation AND CHARACTERISTIC AND THE CHARACTER FROM THE PERSPECTIVE OF TURN-TAKING MECHANISM}

This analyzes the relationship and characteristics of characters from the perspective of turn-taking mechanism in this part. It is the main body of the paper, it included two sections, the first section is to analyze the relationship between characters by using turn-taking mechanism. The second section is the analysis of characteristics of main heroes in the sitcom.

\section{A. Analysis of Relationship between Characters}

This part will introduce the relationship between characters in the sitcom. The relationship between Sheldon and Amy, the relationship between Leonard and Penny.

\section{The Relationship between Sheldon and Amy}

In this section, some conversations will be used to express personalities of Sheldon and Amy, they are lovers, and their relationship can be observed through their conversations. The degree of familiar will be presented by their conversations and the story take place in the situation where Leonard and Amy drive the car to pick Sheldon up at home after Sheldon travelled and his money and objects lost, and Amy seats the back of the car and listen their chat, she is so anger because Sheldon does not explain any words to her, actually Sheldon just does not lose his face in the front of his girlfriend, and that will be express at their conversations.

T1 Sheldon: "Hey, Amy what do you say? You ready move on to the mustard round?"

T2 Amy: "Have you not notice that I have been sitting back here quietly stewing for the past two hours?"

T3 Sheldon: "I just thought you were bad at the game."

T4 Amy: "I am mad at you. How would you go away like that without even saying goodbye and then call Leonard for help instead of me?"

T5 Sheldon: "I called Leonard because I failed I did not you want to think less of me."

T6 Amy: "You are worry about that? It is not ok with that you are not perfect."

T7 Sheldon: I wish I would never go on the trip. I tell no better now than when I let."

T8 Amy: "But you still accomplished something. What if it did not all go your way. That is what makes it an adventure."

T9 Sheldon: "That is a good point. Yeah, I am a lot like Gandalf the Grey. He fought the Balrog and emerged stronger than ever as Gandalf the White. I was robbed my phone and pants, and I too, came back stronger and whiter, too, cause I was in direct sunlight for six weeks."

T10 Amy: "See this trip was good for you."

T11 Sheldon: "Indeed I was the world's smartest caterpillar and then after pupating in our nation's railway system. I have burst forth the world's smartest butterfly."

--(the Big Bang Theory Season 8 Episode1)

In this conversation, both the words of Sheldon and his girlfriend are take sentences serve as a turn. And clearly Sheldon starts a turn and he finishes the turn by self-selection finally. But, we can clearly find that Sheldon starts the turn and selects a person who is his girlfriend to talk it, so the topic is distribute by his girlfriend. In preference organization between Sheldon and Amy, we can use turn-taking mechanism to discover their relationship. Between their talking, they play the roles of the speaker and the hearer, Sheldon gives a request and Amy responds to him, then Amy does so. We can easily find that in the T1, Sheldon asked a question for Amy, but Amy does not answer him, instead, she angers with him, because he does not explain anything to her. So an insertion pair takes place. And Sheldon does not continue to the first topic and give an honest answer for Amy so that he just keeps a perfect impression in Amy's heart. For this Amy very glad to hear these words, so in next conversation, Amy chooses preferred answers to comfort 
Sheldon. Indeed, that way is very useful to Sheldon, and their relationship become more closely.

In the conversation above, Sheldon makes 4 preferred answers, and Amy has 3 preferred answers. In T2, Amy is mad at Sheldon, so she does not answer T1.But in the T5 Sheldon: "I called Leonard because I failed I did not you want to think less of me." It indicates Amy takes an important role in the heart of Sheldon. And in the T6 Amy: "It is not ok with that you are not perfect." It shows that Amy like Sheldon very much whatever the aspect of good or bad.

\section{The Relationship between Leonard and Penny}

Leonard and Penny is another lover in the sitcom, just as different couples have the different ways to get along with each other, so their relationship is very different from Sheldon and Amy, and they have their own happiness. Leonard becomes interested in Penny almost immediately after seeing her for the first time. His infatuation with Penny becomes the major force that drives the series during the first seasons. By the end of the first season, Leonard finally managed to ask Penny out, and they had their first date. And Leonard loves Penny very much. The story about them takes place in the dorm dance after they graduated. Their relationship is harmonious.

T1 Penny: "Well, I might not have asked you to dance then, but I will ask you now."

T2 Leonard: "There is no music."

T3 Penny: "I do not care. We will make our own music."

T4 Leonard: "My God, who is the dork now?"

T5 Leonard: "Thank you for wearing your flats."

T6 Penny: "Thank you for wearing your heels."

T7 Leonard: "Look at me, dancing with the prettiest girl at the prom."

T8 Penny: "Want to take a picture of us and send it to old friends in the chess club?"

T9 Leonard: "I send them a bikini shot of you years ago. That is nice. I kind of wish no one else was coming."

T10 Penny: "I know, nice, too. But it will be fun to have a prom without all the drama."

--(the Big Bang Theory. Season 8 Episode 8)

From these conversations, both of their words are made of sentences, so sentences serve as a turn. A turn is started by Penny and also finished it by herself. Penny chooses a turn, and it is distributed by Leonard. The difference of turn types and preference organizations between Leonard and Penny, it will show their relationships. Penny is a careful girl, she invites her boyfriend to dance and when her boyfriend asks her there is no music in the T2, she responds that she does not care in the T3. From their adjacency pair, T2 and T3 is a pair of insertions, Leonard does not accept her invitation and asks his girlfriend's feeling without music, they are care about each other. Then in the T5 and T6, Leonard thanks his girlfriend's considerateness without wearing heels, and Penny chooses preferred too, because she considers her boyfriend's feeling. From her answer, we easily find the girl is so considerate. And then, his boyfriend opens the other topic and in the T8, and his answer to her friend can show how much he like his girlfriend.

When it comes to the preference structure, there are 3 preferred organizations and 2 dispreferred, but both of those are used to express they love with each other and think about each other. Their relationship is very familiar.

\section{B. Analysis of Characteristics of the Characters}

This part will analysis of characteristics of the characters in the sitcom.

\section{The Characteristics of Sheldon}

Sheldon is one of the important figures in the sitcom, and his intelligence quotient is higher than normal people, however, he is too devoted to the science to have a common sense of life. He is very stubborn and conceited. As the highest nerd of IQ, he has the lowest EQ. Sometimes he is extremely conceited and refuses to believe that there are more intelligent people than him in the world and he believes he never do wrong things.

Because there is a big gap between his IQ and EQ, Sheldon is the funny person in the drama. At the start, his jokes are from his frankness and audiences feel the happy in the deep of their heart and make people laugh. However, his words began to mean, arrogant and annoying. With the development of the story, he starts to realize his defeat and try to change it, he starts to care for others. So, the personalities of the characteristics gradually shaped.

The story takes place at the railway station when his friends want to persuade him into going home, but he does not listen any words and he still stick to his opinions.

T1 Leonard: "We are worry about you."

T2 Sheldon: "Do not be melodramatic. I just getting on the train and leaving forever."

T3 Leonard: "So a few things do not go your way and your best decision is to ride the rails like a hobo?"

T4 Sheldon: "I am overwhelmed. Everything is changed and it is simply too much, I need to go away and think."

T5 Leonard: "I am going to miss you."

T6 Sheldon: "Of course you are."

T7 Leonard: "Just made that easier."

--(the Big Bang Theory Season 8. Episode 1)

From these conversations above, the background is that when Sheldon confronts with many troubles and he wants to leave and he does not listen to his friend's advice, so Leonard just say goodbye to him. Leonard starts the turn to persuade his fiend is stay behind, but it does not work, so he ends the turn by himself. The conversation consists of Sheldon and his friend Leonard who wants to comfort him after a series of bad things happened, and tries to ease him and persuade him into doing not make the impulse thing. In the T1, his friend shows worried about him, and in the T3, 
his friend tries to ease him. However, he failed. In the T2, Sheldon does not chooses preferred answer for his friend, and the answer shows that he is very stubborn, and does not change his decisions easily. Sometimes, he does not face difficulties directly, and instead he avoids it. In the T4, when his friend comforts him, he does not clam down and said "I am overwhelmed. Everything is changed and it is simply too much, I need to go away and think." We can easily find that sometimes he just like a child who is very hard to accept change. In the T7, his friend say he will miss Sheldon, but Sheldon thinks that is a thing his friend should do, so Sheldon is a self-conceited person.

So, from this analysis above all, it is not hard to find Sheldon is stubborn, child-like, and sometimes lack of caring about others.

\section{The Characteristics of Leonard}

Leonard is another big shot in the sitcom and he is portrayed as an experimental physicist, who shares an apartment with colleague and his best friend Dr. Sheldon Cooper. He often wears black framed glasses, low black shoes, a neutral color sports jacket, brown pants and a physics themed T-shirt. Leonard and Sheldon live together for several years, and can accurately explain the behavior of Sheldon. Leonard has a more normal EQ, and also has a high IQ of 173 . He is 24 years old when he gets a doctorate of philosophy. Dr. Hofstadter then relies on him about the experimental particle physics, and his doctoral thesis won the annual award.

He is a kind person who cares for friends and he can tolerate others. When his friends need his help, he must give them a hand. The background is that Sheldon was robbed in his traveling and asked for help from Leonard.

T1 Sheldon: "Hello."

T2 Leonard: "Hey, buddy good to hear your voice."

T3 Sheldon: "I am in Kingman, Arizona, and I need you to come pick me home."

T4 Leonard: "I would love to, but I am just to do yoga with Penny."

T5 Sheldon: "I am in the police station and I was robbed, they took my phone, my wallet, my ipad, everything."

T6 Leonard: "Oh my God, are you ok?"

T7 Sheldon: "No, I am not ok, I am wearing borrowed pants, I do not have ID and one of the policemen won't calling me Chicken legs."

T8 Leonard: "OK, I am will pick you, do you want me bring something?"

T9 Sheldon: "Yes, a pair of pants."

--(the Big Bang Theory Season 8. Episode 1)

This is a conversation between Leonard and his good friend Sheldon. The background is that Sheldon lost his money and other important things in his trip, he just asks for help to his friend Leonard at the police department. So, Sheldon starts a turn for help and ends the turn by himself. There are 2 preferred structures and 2 dispreferred. Leonard is angry with his roommate Sheldon but he is still kind to Sheldon. In the conversation T4, when he heard Sheldon asks him to pick up Sheldon, he is unwilling to go. So he refuses him, but when he knows Sheldon got some troubles, he immediately accepted his demands in the T8. And in the T9, he is very careful to ask his friend what things he need, he said, "I will pick you, do you want me to bring something." From these turns we can clearly see that the relationship between Leonard and Sheldon is very familiar and Leonard always put up with Sheldon and forgive his eccentricities. He does not only have a high IQ, but also his EQ is like other ordinary people, so he more successfully communicates with girls than others in the sitcom.

So, Leonard is a nice boy and he always tolerates his friend, and is kind to other people.

\section{CONCLUSION}

Conversational analysis is an approach to the study of social communication, it include verbal behavior and non-verbal behavior which takes a crucial role in our daily life. And many researchers have researched the turn-taking mechanism from different points. The studies analyses the characteristics and relationships between people in the sitcom, the Big Bang Theory from the perspective of turn-taking. We can find that the characteristics and the relationship of characters not only through the content of their conversations, but also by the turn of dialogue and presequence organization.

In this paper, the author finds out turn-taking features of it. Firstly, turn-constructional components are discussed in the Big Bang Theory. Words, phrases, sentences serve as turns. It can find that characters like to use sentences because sentences can convey more meaning in the sitcom where need to express scene, plot, feeling, or anything so that audiences can get more information about the series. Secondly, turn-allocational components are discussed from two aspects: the current speaker selection and self-selection. Characters in the sitcom ask questions to someone who will answer it and becomes the next turn holder. Turn-allocational components can help break the silence and keep the conversation smoothly. Finally, characters choose preference structure to express their politeness and kindness. However, some characters often use dispreference to answer the speaker and the way can show the characteristics of characters.

And, we use the turn-talking mechanisms to analyze the dialogue of the Big Bang Theory in the paper. After analyzing the conversations between Sheldon and Amy, the conversation between Sheldon and Leonard, also the conversation between Leonard and Penny, we can find it has a closely relationship between turn-taking mechanism and character's personalities. 
Through the analysis of adjacency pairs, preference sequences and presequence organizations, we can find the familiar degree of their relationship between different people.

Different people use different ways to express their ideas. And these expressions they used can distinguish their characteristics. They often used their unique ways to make the conversation continually.

In this paper, the author finds out turn-taking features of it. Firstly, turn-constructional components are discussed in the Big Bang Theory. Words, phrases, sentences serve as turns. It can find that characters like to use sentences because sentences can convey more meaning in the sitcom where need to express scene, plot, feeling, or anything so that audiences can get more information about the series. Secondly, turn-allocational components are discussed from two aspects: the current speaker selection and self-selection. Characters in the sitcom ask questions to someone who will answer it and becomes the next turn holder. Turn-allocational components can help break the silence and keep the conversation smoothly. Finally, characters choose preference structure to express their politeness and kindness. However, some characters often use dispreferred to answer the speaker and the way can show the characteristics of characters.

\section{REFERENCES}

[1] Cook. (1989). Discourse. London city: Oxford University Press.

[2] Harris, Z. S. (1951). Methods in Structural Linguistics. Chicago: University of Chicago Press.

[3] Liu Qingling. (2012). Application of turn taking system in dialogue analysis of Flower girl. Journal of Chi Feng university, 5, 193-196.

[4] Liu Runqing, Wen Xu. (2006). Linguistics: A New coursebook. Beijing: Foreign language teaching and research press.

[5] Li Yuee, Fan Hongya. (2012). Discourse analysis. Shanghai: Foreign language teaching and publication in Shanghai.

[6] Yu Hualu. (2010). The reflection of the American sitcom the big bang. Overseas English, 8, 217-218.

[7] Zhang Tingguo. (2003). Communicative skills of turn taking and turn taking. Foreign language teaching, 24, 23-25.

Tingting Shi was born in Linfen, China in 1993.She is studying for her master's degree in linguistics in Shanxi Normal University in 2017.

She is currently a student the school of Shanxi Normal University. Her research interests include pragmatics and social linguistics. 